\title{
Development and use of educational resource in a pedagogical university on an inter-scientific basis
}

\author{
Peter Khromenkov ${ }^{1}$, Tatyana Yuzefavichus ${ }^{1}$ and Irina Khlyzova ${ }^{1, *}$ \\ ${ }^{1}$ Moscow Region State University, 105005, Radio str, 10A, Moscow, Russia
}

\begin{abstract}
In the presented paper, the key problem of higher education pedagogy is updated, the solution of which allows the transfer of teacher education to a qualitatively new level in the context of inter-scientific interaction.Using the methods of comparative, factor analysis, inductivedeductive, hypothetical and synthetic methods, a model has been developed for the formation of an information-educational resource and its use in the educational process of a university. The originality of this model is characterized by the novelty of the methods for the formation and implementation of the developing potential of the numerous multilateral inter-scientific relations of pedagogy with other human sciences.It is established that the information and educational resource formed on an inter-scientific basis has a developing focus.Its implementation ensures the integration of theteacher educationcontent, the development of a mechanism of inter-knowledge interaction, the formation of complete and holistic, metadisciplinary knowledge, universal professional skills and competencies of students.In accordance with this, the path of organizing integrative educational and cognitive activities through expert development and implementation of a database of people in the educational process of a pedagogical university is substantiated.The advantage and priority of using in the training of future teachers the developing potential of inter-scientific communication in comparison with the traditionally used simplest binary connections of pedagogy and other sciences is proved.The developed technology for teaching students of a pedagogical university in the context of inter-scientific communication using a developing educational resource can be useful to both teachers and masters, graduate students, doctoral students who have mastered the metalanguage culture of conducting educational and scientific research.It can be used in teaching undergraduate and graduate students in other areas and profiles of training.
\end{abstract}

\section{Introduction}

A comparative analysis of the federal state educational standards of higher pedagogical education of the last two generations testifies to their focus on the solution of a twofold key task: the continuous development and improvement of the quality of professional training

\footnotetext{
*Corresponding author: hlizova_iv@mail.ru
} 
of future teachers. Obviously, its successful solution largely depends on the developing function of the educational environment of the university, which, in turn, is uniquely determined by its developing resources $[8,11]$. Of course, a significant role in this among all resources is played by the developing information and educational resource [6].However, the analysis of advanced pedagogical experience and the generalization of university educational practice show that, despite the use of modern information and communication technologies, under the conditions of dominant subject-centered learning, the developing function of the educational resource is manifested to a small extent. Therefore, under these conditions, a noticeable development of pedagogical professionalism of students is not observed. It should also be noted that interdisciplinary integration, as evidenced by the results of studies of the last decade in pedagogy of higher education $[3,4,15]$, is possible only if there is a basic condition - the interaction of more than two academic disciplines. But it, by virtue of traditional training, is not sufficiently implemented in practice. The use in the educational process of unsystematic simple connections of pedagogy with other disciplines only to a small extent contributes to the development of professionally significant knowledge, skills and competencies of students. This conclusion is made taking into account the theoretical justifications of the mechanism and conditions for the synthesis of scientific knowledge in philosophy [5,13], their generalization and development in psychology $[9,14,16,17,18]$ and the results of basic research on the relations of pedagogy in the system of human sciences [2,10,12].It correlates with research results obtained in the theory of the integration of education [1].In this regard, it should be noted that in the development of pedagogical professionalism and the formation of professional competence, as an integrative quality of the personality of a university student, certain contradictions are revealed. They serve as the basis for the formulation of the problem, the solution of which in the conditions of inter-scientific communication is aimed at substantiating the possibilities of bringing the content and function of the information and educational resource into conformity with the tasks of training professionally competent future teachers. Inter-scientific communication is defined by us as a combination of information-cognitive, communication, research and complementary processes in the system of sciences interacting with pedagogy. Its basic structural elements are objects (scientific texts, documents, scientific knowledge, information, data on human sciences), subjects (students, teachers, experts) and numerous multilateral inter-scientific relations of pedagogy. Using the developing potential of inter-scientific communication provides meaningful, methodological, linguistic and conceptual integration in higher pedagogical education. The study focuses on meaningful integration. In our understanding, it is a process and the result of the interaction of inter-scientific knowledge about a human, their complementarity, generalization and synthesis, the development of universal professional skills and competencies of students-future teachers.

In accordance with the problem posed, the aim of the study is the development and implementation of an information and educational resource in a pedagogical university on an inter-scientific basis. To achieve it, the solution of the following main tasks is required: the search for ways to form an informational array of comprehensive data about a human and their objectification in a local automated system if information service for students and teachers, the development of a training technology that ensures the use of a developing informational and educational resource in educational and cognitive activity, and the implementation of pedagogical experiment, evaluation of its results and development of recommendations on the use of developing educational resource under inter-scientific communication. 


\section{Materials and methods}

The solution of the advanced tasks was carried out in stages in accordance with the goal of the study. We will consider that the stages highlighted by us are conditional, since the study was carried out over the past fifteen years, and its results were repeatedly subjected to retrospective analysis, delayed monitoring, refinement and correction in order to determine their objectivity and reliability.

At the first stage, a comparative analysis of fundamental and applied research was carried out on the problems of the complementarity of scientific knowledge, inter knowledge interaction, inter-disciplinary and inter-scientific synthesis in philosophy, psychology, sociology and pedagogy. In parallel, the basic provisions of the theory of information, the theory of educational problems, automated control and management of the educational process were studied. Thus, the theoretical and methodological basis of the study was developed, on which other stages of the work performed were built.

The content of the second stage was a study of how to create a database of interscientific data about a human, in the development of which an expert group of teachers and scientists from the sciences took part: pedagogy, general and age psychology, human anatomy and physiology, sociology and other sciences. The developmental orientation of the educational resource formed on an inter-scientific basis was substantiated. The study was conducted in the laboratory "New Educational Technologies" on the basis of Moscow State Regional University under the guidance of Corresponding Member of the Russian Academy of Education, Honored Scientist, Professor P.I. Pidkasistyy.

Using the methods of inductive-deductive and structural analysis, the study of advanced pedagogical experience in the use of information and communication technologies in higher education, an integrative teaching technology in a pedagogical university was modeled.The development of a model for the use of an educational resource, formed on an inter-scientific basis, was the content of the third stage of the study.

At the final stage of the study, a pedagogical experiment was carried out which was aimed at introducing a model for using the information and educational resource in the educational and cognitive activity of students. Using the methods of mathematical statistics and delayed control, the results of its implementation were evaluated and recommendations were developed for users of the educational product we tested.

\section{Results}

Prior to the development of an educational information resource on an inter-scientific basis, a comprehensive analysis of the educational practice that has developed in pedagogical universities under the conditions of subject-oriented training and interdisciplinary integration has been carried out.It has been established that about $80 \%$ of the classroom time allocated, for example, to the study of general pedagogy is spent on teaching undergraduate students with traditional means and methods with fragmentary use of the simplest pedagogical connections, mainly with psychology, sociology and partly with medicine.It was revealed that during the study of this course, the process of interdisciplinary integration in educational and cognitive activity is extremely rare, the pedagogical knowledge formed itself is not sufficiently complementary and generalized, and interdisciplinary knowledge makes up only $12 \%$ of the volume of professional pedagogical knowledge generated.Moreover, an insufficiently high level of students' knowledge of metalanguage culture was discovered.Most junior and senior students do not prefer the choice of topics for interdisciplinary coursework and diploma studies, whilemastery of metadisciplinary knowledge, generalized skills, universal competencies is provided for by the latest federal state educational standard of higher pedagogical 
education. These and other reliable facts made it possible to holistically assess the state of higher pedagogical education and to outline a way to improve its quality on an interscientific basis. In this regard, a temporary research team was formed, whose members were 7 candidates and doctors of sciences, 5 applicants, graduate students and doctoral students representing human sciences. The theoretical and methodological base of the study was developed and the necessary conditions were created for building a model for the formation of a developing educational resource in the context of inter-scientific communication and its use in the educational and cognitive activities of undergraduate students, which is presented in Figure 1.

development of methodological recommendations on the use of a developing educational resource in a university in the context of inter-scientific communication

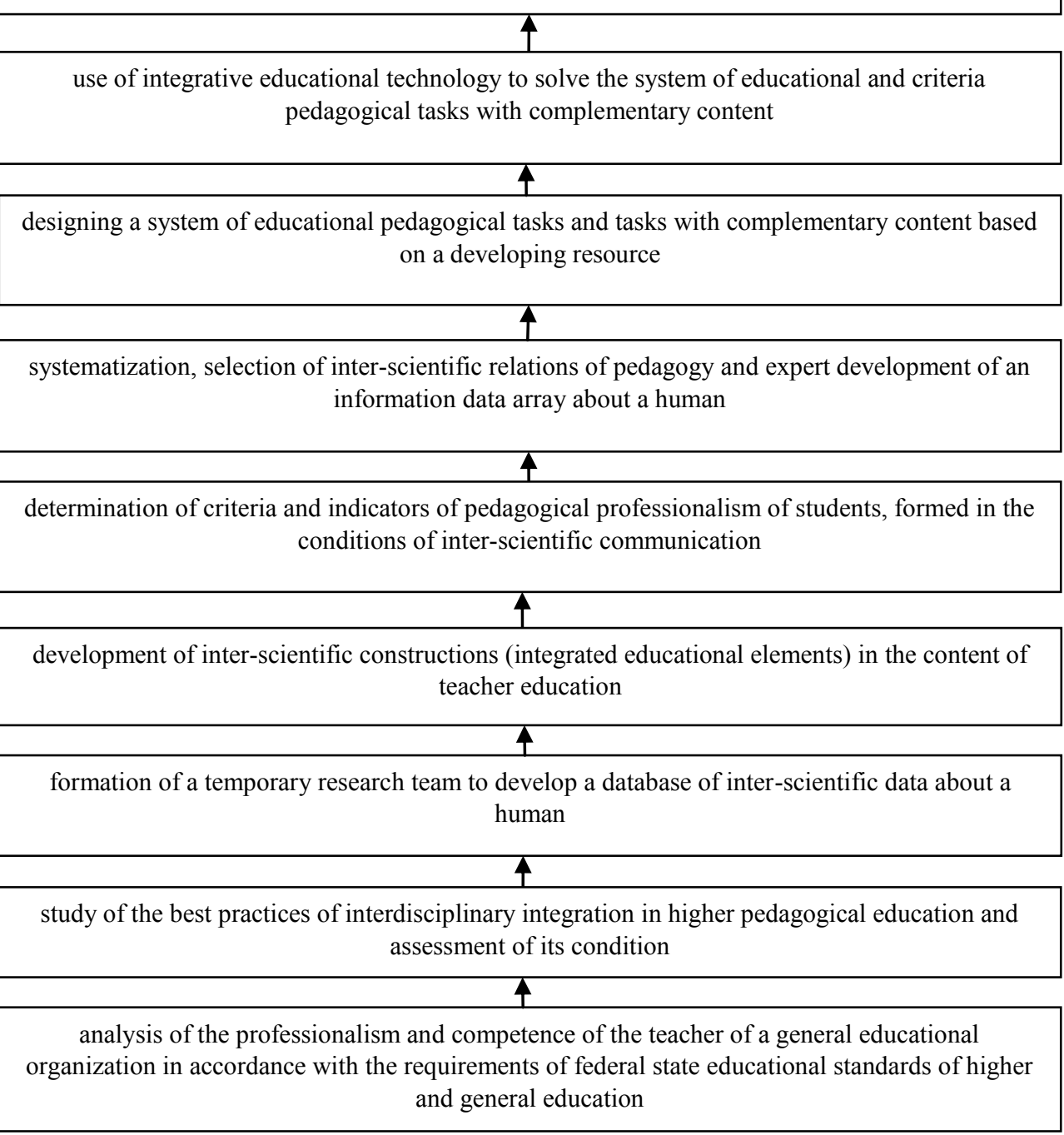

Fig. 1. A model for the formation of a developing educational resource on an inter-scientific basis and its use in educational and cognitive activities.

In accordance with the goals and objectives of their professional and pedagogical training,inter-scientific constructions in the content of teacher education and an integrated 
work program of the discipline "Pedagogue" were developedboom. These constructions include integrated learning elements: age, main periods of life, phylogenesis, factors, conditions and indicators of personality development of the student, pupil.

As criteria for assessing the pedagogical professionalism of students formed in the context of inter-scientific communication, knowledge-based, operational-activity, and competency criteria are defined. The corresponding assessment indicators identified types of knowledge, skills and abilities to master and apply them in practice.

The integrated work program was based on a system of relevant types of inter-scientific relations between pedagogy and the sciences selected by experts. It includes three groups of human sciences: sciences that form the basis for complementarity and the formation of holistic pedagogical knowledge, sciences bordering on pedagogy, and "peripheral" sciences, to one degree or another complementing the field of pedagogical knowledge. Such a system of inter-scientific relations made it possible to objectify inter-scientific information about pedagogical facts, phenomena, processes and systems studied by students in the information array of comprehensive knowledge about a human. The search for ways to objectify it in the information-educational system led to a convincing conclusion about the need to create a database of modern inter-scientific data about a human. The developed base was subjected to repeated expert assessment and was embodied in the local automated control and training system of the university. Its content is the main information and educational resource, which, as was proved with the help of the developed integrative technology, has a developing focus. It was established that the complementarity and inter-cognitive interaction arising in educational and cognitive activities contribute to the synthesis of comprehensive knowledge about a human, that is, the development of a qualitatively new - inter-scientific knowledge, which is the result of the development of this knowledge. It is also proved that the formation of generalized, universal skills and competencies is based on this mechanism of knowledge integration. In addition, it was found that in the process of solving pedagogical problems with complementary content, students develop a metalanguage due to the mastery of the languages of interacting sciences and metalanguage integration.

To verify the feasibility of introducing the model presented in Figure 1 into the educational process of the university, a pedagogical experiment was conducted. Its participants were students of 1, 2, and 4 courses who studied in different training profiles. In total, the experiment involved 758 full-time undergraduate students at Moscow State Regional University. During the experiment, we tested four types of educational and criteria pedagogical tasks with complementary content. The tasks of the first type are intended for students to perform multiple operations in educational and cognitive activities to find close and conjugate semantics in situations where they recognize the inadequacy of own pedagogical knowledge proper for their solution. To the tasks of this type, we attributed the tasks of mastering knowledge and skills to carry out goal-setting, diagnostics, planning, organization, maintenance, management and other professional activities in training and education of different age groups.

The tasks of the second type are aimed at developing a mechanism of inter-cognitive interaction in the students' consciousness and the formation of complementary knowledge necessary for a complete explanation of the studied pedagogical facts, phenomena and processes. Students perform these tasks in practical and seminar classes in pedagogy, special courses, and when writing term projects.

Solving problems of the third type contributes to the elementary mastery of the languages of human sciences, the formation of the simplest inter-scientific knowledge necessary for predicting the individual educational routes of students and pupils. The purpose function of this type of task is to maximize the use of comprehensive, holistic 
knowledge about the development of personal and physiological systems of children studying in a general educational organization, including children with special needs.

The formulation and solution of complementary tasks of the fourth type consists in the development of generalized skills and universal competencies. They are solved by students in educational and professional activities when completing assignments during the period of pedagogical practice in organizing collective and group lesson activities and conducting mass educational creative activities and events.

The development of the listed components of pedagogical professionalism through the application of technology of training using a developing educational resource is carried out, as evidenced by the results of the experiment, in the following stages. The first stage is the objectification of meaningful inter-scientific structures in the information database of a human. The second stage is the differentiation of the learning objective and the formulation of the system of educational tasks with complementary content. The third stage is the solution of complementary pedagogical problems. The fourth stage is the solution of criterial complementary tasks and self-assessment of the success of their solution. At the third and fourth stages, students carry out an information request and are included in the search for the necessary inter-scientific information in the database of inter-scientific data. In the search process, the performed multidimensional measurement of the semantics formed in the consciousness ensures the development of complementary knowledge, its generalization and synthesis.

According to the results of the experiment, a quantitative and qualitative assessment of the formed pedagogical professionalism of students through the use of a developing resource was carried out. It is presented in Table 1. In the educational and cognitive activities during the academic year, students were included in the solution of all types of complementary tasks. In the case of delayed control, students in the control and experimental groups who were studying in the 5th year were offered to solve a system of criterial problems, which included sixty diverse types of complementary tasks. In the control and experimental groups 25 and 25 students respectively studied.

Table 1. The final quantitative and qualitative assessment of the formed pedagogical professionalism of students through the use of a developing resource.

\begin{tabular}{|c|c|c|c|}
\hline \multirow[t]{2}{*}{$\begin{array}{c}\text { Evaluation } \\
\text { criteria }\end{array}$} & \multirow[t]{2}{*}{ Evaluation indicators } & \multicolumn{2}{|c|}{$\begin{array}{c}\begin{array}{c}\text { Number of complementary } \\
\text { tasks solved }\end{array} \\
\end{array}$} \\
\hline & & $\begin{array}{l}\text { control } \\
\text { group }\end{array}$ & experimental group \\
\hline \multirow[t]{6}{*}{$\begin{array}{l}\text { knowledge- } \\
\text { based }\end{array}$} & $\begin{array}{l}\text { knowledge of the development of personal } \\
\text { systems of students, pupils }\end{array}$ & 13 & 20 \\
\hline & $\begin{array}{l}\text { knowledge of the development } \\
\text { physiological systems of students, pupils }\end{array}$ & 6 & 18 \\
\hline & $\begin{array}{l}\text { knowledge of personality development } \\
\text { factors }\end{array}$ & 9 & 19 \\
\hline & $\begin{array}{l}\text { knowledge of the resources of a multicultural } \\
\text { educational environment }\end{array}$ & 4 & 18 \\
\hline & $\begin{array}{l}\text { knowledge of theories, concepts and training } \\
\text { systems }\end{array}$ & 8 & 16 \\
\hline & $\begin{array}{l}\text { knowledge of theories, concepts and systems } \\
\text { of education }\end{array}$ & 11 & 19 \\
\hline \multirow[t]{3}{*}{$\begin{array}{l}\text { operational- } \\
\text { activity }\end{array}$} & $\begin{array}{l}\text { skills and abilities to manage a holistic } \\
\text { educational process }\end{array}$ & 3 & 13 \\
\hline & $\begin{array}{l}\text { skills and abilities to apply health-saving } \\
\text { training technologies }\end{array}$ & 3 & 17 \\
\hline & $\begin{array}{l}\text { skills and abilities to build a multicultural } \\
\text { educational process }\end{array}$ & 4 & 15 \\
\hline
\end{tabular}




\begin{tabular}{|l|l|c|c|}
\hline \multirow{1}{*}{} & $\begin{array}{l}\text { skills and abilities to apply system-type } \\
\text { learning technologies }\end{array}$ & 2 & 14 \\
\cline { 2 - 4 } & $\begin{array}{l}\text { skills and abilities to diagnose goal-setting, } \\
\text { content and results of learning }\end{array}$ & 8 & 18 \\
\hline $\begin{array}{l}\text { skills and abilities to diagnose the integrative } \\
\text { qualities of a person }\end{array}$ & 3 & 19 \\
\hline $\begin{array}{l}\text { competency- } \\
\text { based }\end{array}$ & $\begin{array}{l}\text { abilities to model a holistic educational } \\
\text { process }\end{array}$ & 4 & 16 \\
\cline { 2 - 4 } & $\begin{array}{l}\text { abilitiesto learning in multicultural } \\
\text { environment }\end{array}$ & 7 & 18 \\
\hline $\begin{array}{l}\text { abilities to educate in a multicultural } \\
\text { environment }\end{array}$ & 5 & 19 \\
\hline $\begin{array}{l}\text { abilitiesto build dialogue in a multi-ethnic } \\
\text { environment }\end{array}$ & 2 & 14 \\
\hline $\begin{array}{l}\text { abilitiesto organize collective and group } \\
\text { activities }\end{array}$ & $\begin{array}{l}10 \\
\text { abilitiesto predict and accompany individual } \\
\text { educational routes of students, pupils }\end{array}$ & 5 & 17 \\
\hline
\end{tabular}

For each of the three criteria, those indicators were selected that, in our opinion, allow us to holistically evaluate the pedagogical professionalism of university graduates, developed on an inter-scientific basis. It should be noted that at different stages of using integrative teaching technology, students solved diverse types of complementary educational tasks of different levels of training, depending on the degree of development of analytical and synthetic skills, cognitive style, knowledge of information searching skills, basic pedagogical knowledge, educational and scientific languages of pedagogy, languages of human sciences. The obtained data characterizing this dependence in the control and experimental (in brackets) groups are presented in Table 2. The results of the experimental work were evaluated on a 10-point scale at three given levels. Obviously, the dispersion characterizing the obtained indicators at three levels of the organization of educational and cognitive activity of students is appropriate of both the control and experimental groups, but the values of the indicators of the second group of recipients are noticeably higher compared to the indicators of the first group.

Table 2. Factor dependence of the levels of integrative educational and cognitive activity formation on an inter-scientific basis.

\begin{tabular}{|c|c|c|c|}
\hline \multirow{2}{*}{$\begin{array}{c}\text { Formation factors of } \\
\text { pedagogical } \\
\text { professionalism on an } \\
\text { inter-scientific basis }\end{array}$} & \multicolumn{3}{|c|}{$\begin{array}{l}\text { The results of the organization of integrative educational and } \\
\text { cognitive activities }\end{array}$} \\
\hline & $\begin{array}{c}\text { I level: } \\
\text { knowledge of } \\
\text { inter-scientific } \\
\text { knowledge }\end{array}$ & $\begin{array}{l}\text { II level: knowledge } \\
\text { of universal } \\
\text { (generalized) skills } \\
\text { and abilities }\end{array}$ & $\begin{array}{l}\text { III level: } \\
\text { knowledge of } \\
\text { metalanguage }\end{array}$ \\
\hline $\begin{array}{l}\text { knowledge of information } \\
\text { retrieval skillsand abilities }\end{array}$ & $5.3(7.8)$ & $5.8(8.8)$ & $3.3(8.6)$ \\
\hline $\begin{array}{l}\text { presence of analytical and } \\
\text { synthetic abilities }\end{array}$ & $6.4(6.9)$ & $5.4(8.9)$ & $3.7(6.1)$ \\
\hline cognitive style & $4.9(7.7)$ & $3.7(8.3)$ & $5.2(6.3)$ \\
\hline basicpedagogicalknowledge & $3.3(8.2)$ & $3.3(7.4)$ & $1.7(6.0)$ \\
\hline $\begin{array}{lcc}\begin{array}{l}\text { knowledge } \\
\text { educational }\end{array} & \text { of } & \text { the } \\
\text { pedagogy } & & \text { of }\end{array}$ & $5.1(6.9)$ & $2.5(5.7)$ & $2.6(7.1)$ \\
\hline $\begin{array}{l}\text { knowledge of the scientific } \\
\text { language of pedagogy }\end{array}$ & $6.0(8.5)$ & $3.9(7.0)$ & $5.1(7.2)$ \\
\hline $\begin{array}{l}\text { language proficiency in } \\
\text { human sciences }\end{array}$ & $5.3(8.0)$ & $4.7(8.7)$ & $4.9(9.1)$ \\
\hline
\end{tabular}




\section{Discussion}

A comparative analysis of the data of the control and experimental groups (Table 1) shows that under the conditions of traditional training, using the potential of individual disciplines interacting with pedagogy, the number of complementary tasks correctly solved by students is 3-6 times less than the students of the experimental group. We believe that, judging by the number of tasks solved, the low level of professionalism of future teachers in such indicators as: abilities and skills to apply system-type technologies in training (2 tasks), manage a holistic educational process ( 3 tasks), health-saving technologies (3 tasks) and other indicators due to the lack of complementary and inter-scientific knowledge among students. This regularity is manifested in the analysis of the data in Table 2. Indeed, the lowest points are corresponded to the formed inter-scientific knowledge (3.3 points), universal skills and abilities ( 2.5 points, 3.3 points), possession of a metalanguage (1.7 points, 2.6 points) in connection with the one-sidedness of the basic pedagogical knowledge and the isolation of the educational language of pedagogy in the context of subject-oriented learning. This indicates that in the control group in the consciousness of students there is no mechanism of inter-cognitive interaction and a metalanguage is not developed. These indicators for the experimental group are much higher. Thus, turning to the results of the pedagogical experiment, we became convinced of the advisability of using in practice the model we developed for the formation of the information and educational resource and its use in the educational process of the university. It should be emphasized that the development of the problem posed was rather laborious, but productive, and the results obtained are innovative in comparison with the practice of organizing interdisciplinary interaction in the context of traditional education. Of course, the results of the work done enrich the theory and practice of higher pedagogical education to a certain extent in modern sociocultural and economic conditions. The underestimation in the pedagogy of higher education of the role of inter-scientific communication does not contribute to the development of its subject, methods and language, while the science of pedagogy has an inter-scientific nature. Any educational technology of the system type can provide high results of teacher education if it is developed on the basis of using the developing potential of the educational resource of the university. We consider the search for ways of its highquality development, based on updating and comprehensive use of modern human knowledge in the preparation of competent teachers, as a priority strategic task for further research of the problem posed by us.

\section{Conclusions}

The results of the study allow us to conclude that the quality of professional and pedagogical training of university students in the conditions of inter-scientific interaction depends on the implementation of a developing educational resource. It can be formed and used in educational and cognitive activities by identifying the developing potential of many sciences interacting with pedagogy. The systematic use of numerous and multilateral interscientific relations of pedagogy in the educational process of a university contributes to the integration of the content of teacher education, provides a developing focus of the formed pedagogical professionalism of students. To build an integrative educational and cognitive activity requires the use of an information array of data from the interacting sciences about a human through the development and application of teaching technology that provides a systematic solution to pedagogical problems with complementary content. To improve the quality of the information and educational resource, formed on an inter-scientific basis, the participation of experts is required - representatives of various human sciences. The educational product obtained as a result of the study can be successfully used by teachers of 
higher education, scientists involved in the development of this problem. Having completed the study, we have reason to formulate some methodological recommendations for users of our educational product: the subjects (students, teachers) of inter-scientific communication included in the educational process should at least at the initial level be proficient in the languages of human sciences and basic metalanguage culture, to develop and improve the quality of a developing educational resource on an inter-scientific basis, it is extremely necessary to attract experts - representatives of different human sciences.

\section{References}

1. A.Ya. Danilyuk, Theory of Education Integration (Rostov-on-Don, Publishing House of the Rostov Pedagogical University, 2000)

2. V.I. Zhuravlev, Pedagogy in the system of human sciences (M., Pedagogy, 1990)

3. L.S. Znikina, P.A. Strelnikov, Bulletin of Kostroma State University named by N.A. Nekrasov 2, 197 (2014)

4. M.N. Kicherova, S.I. Chernomorchenko, Bulletin of the Leningrad State University named by A.S. Pushkin 4, 308 (2017)

5. B.M. Kedrov, V.P. Smirnov, The interaction of sciences: theoretical and practical aspects (M., Mysl', 1984)

6. A.M. Kondakov, Education as a resource for the development of the individual, society and the state: dissertation of a doctor of pedagogical sciences (M., 2005)

7. N.I. Kuznetsov, a Higher education in Russia 3, 59 (2017)

8. L.I. Larionova, Psychology. Historical and critical reviews and modern research 6(6A), 50 (2017)

9. V.A. Mazilov, Yaroslavl Pedagogical Bulletin 4.V.II, 201 (2013)

10. E.I. Snopkova, Scientific dialogue. Pedagogy.Psychology 6(30), 82 (2014)

11. Yu.V. Tyagunova, Bulletin of the South Ural State University. Series "Education. Pedagogical sciences" 18(41), 18 (2012)

12. K.D. Ushinsky, Collected works (M.-L., Publishing House of the APN of the RSFSR, 1950)

13. I.T. Frolov, About man and humanism (M., Science, 2003)

14. M.A. Kholodnaya, G.V. Ozhiganova, Mental resources of the individual: theoretical and applied research: materials of the third International Symposium (M., Institute of Psychology RAS, 2016)

15. L.A. Shestakova, Bulletin of Moscow University named by S.Yu. Witte. Series 3: Pedagogy. Psychology. Educational resources and technology 1(2), 47 (2013)

16. G.P. Shchedrovitsky, Synthesis of knowledge: problems and methods (M., School of Cultural Policy, 1995)

17. V.I. Dobrosotskiy, G.N. Semenova, E.B. Kazarinova, N.V. Falina, On the Horizon 27(3/4), 213 (2019) https://doi.org/10.1108/OTH-07-2019-0035

18. E. Ganebnykh, I. Altsybeeva, and E. Gurova, SHS Web of Conferences 35, 01029 (2017) DOI: $10.1051 /$ shsconf/20173501029 